Running head: TEACHER VICTIMIZATION AND TURNOVER

ACCEPTED VERSION - PLEASE CITE PUBLISHED VERSION AS:

Curran, F. C., Viano, S. L., \& Fisher, B. W. (2017). Teacher victimization, turnover, and contextual factors promoting resilience. Journal of School Violence, 1-18.

Teacher Victimization, Turnover, and Contextual Factors Promoting Resilience

\author{
F. Chris Curran* \\ Assistant Professor of Public Policy \\ UMBC School of Public Policy \\ University of Maryland, Baltimore County \\ 1000 Hilltop Circle \\ \#411 Public Policy Building \\ Baltimore, MD 21225 \\ curranfc@umbc.edu \\ $615337-6854$ \\ Samantha L. Viano \\ Graduate Student \\ Vanderbilt University \\ 230 Appleton Place, PMB 414 \\ Nashville, TN 37204 \\ samantha.viano@vanderbilt.edu \\ 336 413-0786 \\ Benjamin W. Fisher, PhD \\ University of Louisville \\ Rm 210 Brigman Hall \\ Louisville, KY 40292 \\ ben.fisher@louisville.edu \\ 502 852-6732
}

*Corresponding author 


\begin{abstract}
Teacher victimization is a relatively understudied phenomenon that the literature suggests may contribute to teacher turnover. The purpose of this study is to explore the relationship between teacher reports of victimization and teachers leaving the school and the profession. Using nationally representative data $(n=104,840)$ from the Schools and Staffing Survey, we examine the extent to which being threatened or attacked by students predicts higher rates of teacher turnover and whether this relationship differs due to factors that may promote teacher resilience. We utilize conditional multinomial logistic regression, implicitly controlling for school-by-year fixed effects. Findings suggest that perceived victimization predicts an increased probability of leaving the school and profession. School-level promoters of resilience are found to mitigate this relationship. We discuss ways schools can mitigate the impact of victimization. This work contributes to a nascent body of literature on teacher victimization and informs a policy lever by which turnover may be reduced.
\end{abstract}

\title{
Keywords
}

teachers, attrition, retention, attack, threat 


\section{Teacher Victimization, Turnover, and Contextual Factors Promoting Resilience}

School safety has garnered much attention from policymakers and the public in recent years. School leaders have responded by implementing various security measures, disciplinary policies, and other interventions aimed at improving school safety (Zhang, Musu-Gillette, \& Oudekerk, 2016). Simultaneously, researchers have been building a body of literature around constructs related to school safety, including security measures, behavioral interventions, and other policies aimed at enhancing school safety (Cornell \& Mayer, 2010). Despite this increased attention, the conversation around school safety has focused largely on the safety of students, with less attention to the safety of other key school personnel, such as teachers (Espelage et al., 2013). What evidence does exist, however, suggests that teacher safety is a salient component of the school environment and may be an important consideration for educational policymakers. There are discrepancies in prior literature as to the extent to which teachers are victimized in the United States. For instance, evidence from a national survey of teachers revealed that about $80 \%$ reported experiencing some form of victimization at school in the past year, including verbal harassment, theft, damage to property, or physical victimization (McMahon et al., 2014). Other data indicate that in the 2011-12 school year, nine percent of public school teachers reported being threatened with injury by students at school while five percent experienced a physical attack by students at their school (Zhang et al., 2016). In this study, we focus on two types of teacher victimization - verbal threats of injury and physical attacks by students.

Despite the prevalence and ubiquity of teacher experiences with victimization, the topic of teacher safety has received little attention from policymakers or researchers, particularly in the United States (Espelage et al., 2013). Though limited, this research has indicated that teacher victimization is associated with impaired work performance and emotional issues (Shernoff, 
Mehta, Atkins, Torf, \& Spencer, 2011; Wilson, Douglas, \& Lyon, 2011). Such findings and the lack of attention to teacher safety are particularly alarming given that teachers are one of the single most important measurable school factors predicting student achievement (Nye, Konstantopoulous, \& Hedges, 2004; Rivkin, Hanushek, \& Kain, 2005). Nevertheless, it is likely that the consequences of teacher victimization could differ across school contexts, particularly in response to working conditions. Working conditions play an important role in teachers' decisions to remain in their school and profession (Grissom, 2011; Ladd, 2011; Johnson, Kraft, \& Papay, 2011), indicating that there may be school-level factors that can mitigate the negative effects of victimization. The purpose of this study is to explore the relationship between teacher reports of victimization and teachers' likelihood to remain teaching in their school or to remain in the teaching profession. We also consider the extent to which school promoters of teacher resilience might mitigate the relationship between victimization and turnover.

\section{Teacher Turnover and the Role of Working Conditions}

\section{Teacher Turnover}

Teacher turnover occurs when a teacher leaves a school to either teach at another school or to leave the teaching profession entirely. Over the past several decades, the teaching profession has suffered high turnover rates, and the trend continues to worsen. Following the 1990-91 school year, about $12 \%$ of all public school teachers left their school, whereas after the 2011-2012 school year, about 16\% of teachers left their school (Goldring, Taie, Riddles, \& Owens, 2014; Keigher, 2010). In the year following the 2011-12 school year, these leavers were almost evenly split between leaving their school to teach in a different school (8.1\%) and leaving the teaching profession entirely (7.7\%; Goldring et al., 2014). 
Evidence suggests that high levels of teacher turnover contribute to lower student achievement (Ronfeldt, Loeb, \& Wykoff, 2013). Moreover, teacher turnover occurs disproportionately in schools serving larger minority or low socio-economic status student populations, potentially perpetuating achievement gaps (Borman \& Dowling, 2008; Guarino et al., 2006; Hanushek, Kain, \& Rivkin, 2005; Hughes, 2012; Ingersoll, 2001; Ladd, 2011; Lankford, Loeb, \& Wyckoff, 2002; Loeb, Darling-Hammond, \& Luczak, 2005). To the extent that teacher experiences of victimization contribute to increases in teacher turnover, their victimization may result in a churn of teachers that disrupts the stability of schools and results in decreased achievement.

\section{Teacher Turnover Determinants}

The existing literature on the determinants of teacher turnover has largely examined the role of teacher and school characteristics. Teacher characteristics such as age, race, gender, and specialty field are predictive of whether a teacher will stay, move schools, or leave teaching altogether (Borman \& Dowling, 2008; Guarino, Santibanez, \& Daley, 2006; Ingersoll, 2001). Turnover rates are elevated when teachers are below thirty or above fifty years old (Borman \& Dowling, 2008; Guarino, Santibanez, \& Daley, 2006; Ingersoll, 2002). Female, married teachers who recently had a child have high attrition rates (Borman \& Dowling, 2008; Guarino et al., 2006; Kirby, Berends, \& Naftel, 1999; Stinebrickner, 1998, 2001, 2002). Teachers with traditional teaching backgrounds and regular credentials are more likely to remain in teaching, while some evidence suggests that math, science, and highly educated teachers might be more likely to leave (Borman \& Dowling, 2008; Darling-Hammond, 2000; Ingersoll, 2001; Ingersoll \& May, 2012; Johnson \& Birkeland, 2003). The findings on racial differences in teacher turnover vary. Although studies using data sets prior to around 2005 found that white teachers 
have higher turnover rates than teachers of color, more recent empirical studies found the opposite result with teachers of color having similar or slightly higher turnover rates than white teachers (see Achinstein, Ogawa, Sexton, \& Freitas, 2010).

In addition to characteristics of individual teachers, studies of teacher mobility and attrition find that working conditions are a key factor driving teachers' decisions to stay or go (Ladd, 2011; Loeb et al., 2005). Working conditions represent the relationships within a school, school leadership decision-making, general condition of facilities, and the safety of the work environment. For example, Grissom (2011) found higher rates of turnover in schools that serve student populations with more minority and/or low income students, have larger enrollments, are urban, and have less experienced and effective principals. Although it appears high-minority, high-poverty schools have higher teacher turnover rates, this finding is driven by poorer average working conditions at these schools (Johnson, Kraft \& Papay, 2011). While some evidence suggests that teachers who feel unsafe or experience victimization may be more likely to leave teaching (Wilson et al., 2011; Zurawiecki, 2013), the relationship between teacher victimization and turnover has not been thoroughly explored, though such victimization may be a salient part of many teachers' working conditions.

In summary, a teacher's likelihood of remaining in a school or in the profession is affected by both characteristics of the teacher and characteristics of the school. Teacher victimization may be an important component of teachers' working conditions that may contribute to teacher turnover. We explore this possibility while grounding the covariates used in our analysis in this rich body of literature in order to control for confounding contributors to teacher turnover.

\section{Teacher Victimization}


Current research on teacher victimization indicates that it is a widespread problem in schools. In a systematic review of extant research on teacher victimization, Espelage et al. (2013) found that violence against teachers is common and consistent over time. However, they also highlighted the dearth of research in this area, stating that, "Violence against teachers is a significant yet under-investigated problem in the United States that has profound implications for schools, teacher retention, and overall student performance” (Espelage et al., 2013, p.84).

In a nation-wide, though not necessarily nationally representative, survey of teachers in $2010,80 \%$ of teachers reported being victimized at least once in the previous or current school year, with 44\% being physically attacked (McMahon et al., 2014). Nearly three quarters of all teachers reported being harassed and 54\% experienced property offenses. Teachers reported being victimized most often by students but also by parents and colleagues (McMahon et al., 2014). The victimization rates in this study are exceptionally high likely due to the measures of victimization. The measures of victimization used in the survey were broad, including harassment, property damage or theft, and the perpetrator could be students or any other person at the school or in the community. Results from another study utilizing a more restricted definition of victimization demonstrate that a meaningful proportion of teachers report serious danger to their physical being. Specifically, findings from the Schools and Staffing Survey (SASS) indicated that nine percent of teachers had been threatened with injury and five percent were physically attacked by a student at their school in the 2011-12 school year (Zhang et al., 2016). The rate of threats of injury by students towards teachers ranged from $3 \%$ in North Dakota to nearly $17 \%$ in Washington, D.C. (Zhang et al., 2016).

Other studies have identified school-level variables associated with teacher victimization rates. For example, findings linking school climate to teacher victimization have come from the 
Virginia Secondary School Climate Surveys, a series of surveys of random samples of students and teachers in Virginia. In a study including ninth grade students and their teachers from 314 high schools, the authors found that clarity and consistency of school rules and administrative support of teachers were associated with less teacher victimization. In particular, administrative support was a consistent predictor of decreased threats against teachers (Gregory, Cornell, \& Fan, 2012). These results were replicated in a follow up study including all teachers in 389 Virginia middle schools where teachers in schools with consistent rule enforcement and supportive teacher-student relations reported lower levels of student aggression against teachers (Berg \& Cornell, 2016). A state-wide study from Kentucky, the Rural Substance Abuse and Violence Project, surveyed 1,438 teachers from 54 public high schools and found that teachers' perceptions of safety were negatively correlated with student misconduct (Roberts, Wilcox, May, \& Clayton, 2007). Survey data from a nationwide survey of teachers in 2010 (the same used by McMahon et al., 2014) examined correlates of teachers reporting multiple victimization incidents. This analysis found that more years of teaching experience and higher levels of administrative support predicted fewer victimization incidents. Engaging in self-blame (i.e., attributing the victimization incidents to their own actions) and teaching in urban areas predicted more victimization incidents (Martinez et al., 2016).

Although the extant teacher turnover literature has focused on attributes that have importance to teachers when making career decisions (e.g., age, credential marketability, and working conditions) there are a number of reasons we would expect teacher victimization to be an important factor in teachers' turnover decisions. In studies of workplace victimization outside of education, workers who experience victimization at work are less satisfied and have higher intentions to turn over (Berthelsen, Skogstad, Lau, \& Einarsen, 2011; Deery, Walsh, \& Guest, 
2011; Einarsen \& Raknes, 1997; Hershcovis \& Barling, 2009; Morrison, 2008). For instance, a study of nurses in the United Kingdom found that harassment at work produced higher turnover intention, although the characteristics of the perpetrator had differential associations with turnover intention (Deery et al., 2011). However, this literature suffers from its use of turnover intention - rather than actual turnover — as shown by Berthelsen et al. (2011) who found that bullying victimization was associated with higher turnover intention for Norwegian workers but that most victims were still working at the organization two years later.

\section{Contextual Promoters of Resilience}

Another aspect of working conditions that may be associated with teacher turnover is the extent to which the school promotes resilience among teachers. Teacher resilience is a relatively new field of research but has been consistently linked to lower feelings of burnout and an increased likelihood to stay in the profession, even in the midst of difficult teaching environments (Aloe, Amo, \& Shanahan, 2013; Gu \& Day, 2007; Howard \& Johnson, 2004; Wei, 2012). Resilience may be defined as "a class of phenomena characterized by good outcomes in spite of serious threats to adaptation or development" (Masten, 2001, p. 228). Resilience is a multidimensional construct that is largely dependent on context and may change over time for a given individual (Hunter, 2001; Luthar, Doernberger, \& Zigler, 1993). Some scholars have focused on how teachers in particular may demonstrate resilience. Mansfield, Beltman, Price, and McConney (2012) suggest that there are at least four dimensions to teacher resilience, including profession-related, emotional, motivational, and social dimensions. The extent to which any given teacher may draw on these dimensions of resilience varies depending on a variety of personal and environmental factors. Although it is difficult to measure resilience 
itself, researchers of resilience have identified a set of environmental promoters of resilience, which is a focus of the current study.

Beltman and colleagues (2011) identified six school and professional environmental factors that fostered resilience among teachers, each addressing interpersonal relationships of some kind. These six factors included school/administrator support, mentor support, support of peers and colleagues, support of family and friends, support from students, and support from a teacher's pre-service program. A variety of environmental challenges also exist for teachers. Some of the most common challenges mentioned in prior research are issues with classroom management or disruptive students, meeting the needs of disadvantaged students, having an unsupportive or disorganized administration, lack of resources, a heavy workload, relationships with parents, and working in a difficult school or class (Beltman et al., 2011). Similarly, Tusaie and Dyer (2004) suggest that two particularly salient environmental factors that affect resilience are perceived social support and the number and recency of negative life events. To date, research has not systematically examined the extent to which these environmental facets of resilience serve to influence victimized teachers' decisions to return to their school.

Although research on the relationship between turnover and victimization is still evolving, to our knowledge, this hypothesis has only been tested among teachers in one unpublished study. Zurawiecki (2013) found that teachers who are victimized by students are more likely to leave their school (but not the teaching profession) the following school year. We build on Zurawiecki's (2013) findings in several ways. First, we use a larger nationally representative dataset that allows us to investigate teacher turnover and victimization for data spanning multiple years. Second, Zurawiecki (2013) utilized a single victimization measure while we disaggregate victimization into student threats and student attacks. Looking at threats 
and attacks separately is important because of the evidence on differential effects of different kinds of victimization (Bond et al., 2007; Strøm, Thoresen, Wentzel-Larsen, Hjemdal, et al., 2013; Strøm, Thoresen, Wentzel-Larsen, \& Dyb, 2013). Additionally, we control for more potential sources of omitted variable bias by including school-by-year fixed effects. Finally, we also contribute a specific theoretical framework to investigate whether working at schools with characteristics that are hypothesized to increase resilience mitigates the relationship between victimization and turnover.

\section{Method}

\section{Data}

We draw on data from multiple iterations of the Schools and Staffing Survey (SASS), a repeated cross-sectional nationally representative survey of schools given periodically since 1987. Each iteration of the SASS contains survey responses at the district, school, principal, and

teacher level. For the purposes of this study, we utilize teacher level data from three iterations of the SASS, specifically the 1999-2000, 2003-2004, and 2007-2008 survey years. We do not include the earlier waves of SASS data because key covariates we use in this study were not included in those datasets.

The SASS contains teacher-reported information on experiences of victimization as well as information on the status of teachers one year after the initial survey (teaching in the same school, teaching at a different school, or left the teaching profession). For the purposes of the primary analyses, we utilize a sample of approximately 104,840 (rounded to comply with IES restricted data requirements) teachers who had data on our victimization measure, teaching status in the following year, and control variables. Our use of list-wise deletion resulted in the loss of approximately $15 \%$ of observations from the original dataset of approximately 123,050 teachers. 
Given the large sample size, list-wise deletion did not run the risk of substantively hurting statistical power (Allison, 2002).

As shown in Table 1 and given that the SASS is nationally representative, our sample reflects the teaching force nationwide in that it is predominantly female, predominantly White, and consists of predominantly regularly certified teachers. In some specifications, our sample size is further restricted $(n=59,920)$ to schools with sampled teachers who both left the profession and moved schools. This choice was made to allow for the use of conditional multinomial logistic regression models which restrict estimates to variation within school-byyears. As explained further in the methods section, this approach is the most appropriate method for modeling multiple outcomes while addressing unobserved sources of omitted variable bias that may exist across schools. In the following sections, we describe the variables of interest.

\section{Measures}

Victimization. As a part of the SASS, sampled teachers responded to several survey items regarding their experiences with victimization in the school environment. We focus on two questions related to threats and attacks in the previous school year. In particular, the SASS asks teachers the following two questions: "Has a student from this school threatened to injure you in the past 12 months?" and "Has a student from this school physically attacked you in the past 12 months?". We use responses to these questions to create two indicators of victimization, one representing threats and another representing attacks. Specifically, the two independent variables are binary indicators of whether the teacher has been threatened with injury by a student in the last 12 months and whether the teacher has been physically attacked by a student in the last 12 months. 
Table 1 provides descriptive statistics on the victimization measures for the analytic sample. As shown, approximately one in twelve (8\%) teachers reported being threatened by a student in the previous twelve months while about half as many (4\%) reported being physically attacked by a student in that time frame. These victimization rates are lower than those reported in other studies likely due to the wording of the items restricting the perpetrator to students (colleagues, parents, community members cannot be perpetrators with the wording of these items) and the severity of the victimization (threatened with injury or physically attacked). The table also provides evidence on the characteristics of teachers reporting experiencing victimization and school contexts in which they work. For instance, teachers who report experiencing an attack were slightly more likely to be a female than teachers who did not report experiencing an attack while teachers reporting experiencing a threat were more likely to be male than teachers not reporting experiencing a threat. On average, black teachers were slightly more likely to report experiencing assault or threats. Teachers with a master's degree and teachers with regular state certification were less likely to report being attacked and threatened.

In addition to teacher characteristics, the frequency of reported threats and attacks on teachers varied across school contexts. In particular, teachers reporting incidents of victimization were more likely to be in schools serving higher proportions of traditionally at-risk or disadvantaged student populations. As shown in Table 1, teachers who reported a threat or assault were more likely to be serving in schools with larger proportions of Black or Hispanic students. Likewise, teachers who reported a threat or assault were more likely to be teaching in schools with higher proportions of students eligible for free or reduced price lunch, a common proxy for student poverty. Additionally, teachers who reported being assaulted by students were more likely to be teaching in elementary settings than middle or high school settings. 
Turnover. Our outcome variable of interest is an indicator of teacher turnover from the profession or from their individual school. We utilize a categorical indicator representing whether a teacher remained teaching in their school, moved to a different school, or left the teaching profession. This measure came from a principal report on the roster of teachers that took part in the SASS during the prior year. As shown in Table 1, on average, 9\% of sampled teachers left the profession between the initial survey and the following year while $7 \%$ of teachers remained in the profession but moved to a different school. Table 1 also shows the descriptive statistics by whether the teacher reported being attacked or threatened in the previous twelve months. As shown, rates of turnover are higher for teachers who report being victimized by students.

Promoters of resilience. We operationalize promoters of resilience through a factor analysis of relevant measures included in the SASS. The bottom section of Table 1 shows the contributors to resilience measures chosen from the SASS that align with the literature on resilience. We factor analyzed eight items which included teachers' ratings of the administrator support, parental support, administrative enforcement of rules, teacher enforcement of rules, shared beliefs among teachers, cooperation among teachers, interference of misbehavior with teaching, and recognition for a job well done (see Appendix A for exact wording of questions). All of the items are measured at the teacher by school by year level. We utilize a single factor derived from these items that represents the degree of external promoters of teacher resilience. The factor analysis yielded a single factor with an eigenvalue above 1 (eigenvalue $=2.85$ ) and factor loadings of the individual measures ranged in magnitude from 0.36 to 0.70 .

\section{Analytic Strategy}


In an ideal study, we would be able to isolate the effects of experiencing victimization on turnover by randomly assigning teachers to experience victimization or not. In other words, we would be able to estimate the effects of victimization holding all else constant. Given, however, that such a study is not logistically or ethically possible, we instead employ a series of statistical models using secondary data to attempt to as nearly approximate the ideal of a randomized experiment as possible. We recognize that teachers who experience victimization and schools where victimization occurs may be different from those without victimization in a number of ways. The goal of our analytic approach is to account for as many of these differences as possible in order to more accurately identify the likelihood of turnover that is driven by victimization. In this section, we outline such an analytic approach that accounts for a number of both observable and unobservable potential confounders.

We model the relationship between reported teacher victimization and the turnover measures through a series of multinomial logistic regression models. Multinomial logistic regression allows for the prediction of a categorical outcome variable (Chamberlain, 1980 p.231). This modeling approach, which is an extension of logistic regression, is appropriate for our categorical outcome as we have three possible outcomes: remaining in the same school, moving schools, or leaving the profession. Our first set of models, therefore, utilizes multinomial logistic regression with a progressive set of control variables. We show models with no controls, with teacher characteristics as controls, with school/district characteristics as controls, and with a year fixed effect (given our use of multiple waves of the SASS). Year fixed effects implicitly control for all fixed aspects of teachers and schools within a given year by basing estimates off of variance within years. For instance, the year fixed effect implicitly controls for the extent that all teachers were impacted by the economic downturn of the Great 
Recession in the 2007-08 wave of the data. All of the controls correspond to those listed in Table 1.

In our final set of models, which we refer to as the fully specified model, we employ conditional multinomial logistic regression (also known as multinomial logistic regression with fixed effects) which extends the multinomial logistic model to include fixed effects (Chamberlain, 1980). We condition on school-years, allowing for implicit control of all fixed characteristics of schools in a given year. This model bases estimates off variance within a given school in a given year and serves to further reduce sources of omitted variable bias. In other words, this model estimates turnover by comparing teachers in the same school during the same school year who experienced victimization to those that did not. This approach, therefore, implicitly controls for unobserved aspects of the school, such as the school climate, disciplinary structure, or other school specific policies. The drawback of using this approach, as noted in the Data section, is that schools that do not have at least one teacher sampled in each of the three mobility categories (staying, moving, and leaving) are dropped from the analysis insofar as they include no within school-by-year variance to contribute to estimates. While this tradeoff reduces efficiency of the estimates, it increases the internal validity of the estimates by controlling for more potential confounders.

Our primary model takes the form of equation 1 below.

1) Turnover $_{t y s}=\beta_{0}+\beta_{1}$ Attacked $_{t y s}+\beta_{2}$ Threatened $_{t y s}+\beta_{3}$ TeacherChars $_{t y s}+\beta_{4}$ SchoolChars $_{s y}$ $\beta_{5}$ SchoolYears ${ }_{s y}+e_{t y s}$

Where Turnover is a categorical variable representing whether the teacher remained teaching at the school, moved to teach at a different school, or left the teaching profession in the following year for teacher $t$ in year $y$ in school $s$, Attacked is a binary indicator for whether the teacher 
reported being attacked in the previous twelve months, Threatened is a binary indicator for whether the teacher reported being threatened in the previous twelve months, TeacherChars is a vector of teacher level characteristics, SchoolChars is a vector of school/district characteristics, SchoolYears is a school-by-year fixed effect introduced through the conditional logit, and $e$ is an error term. We show models where we include both the attack and threatened independent variables together while in others we include each independently.

The coefficients of interest are $\beta_{1}$ and $\beta_{2}$ which, if modeled correctly, can be interpreted as the relationship between reporting being attacked or threatened and turning over from the school or profession after controlling for confounding teacher and school characteristics. In a multinomial logistic regression model, the estimated coefficients are interpreted as changes in the logged odds of the outcome. For interpretation, corresponding odds ratios $(O R)$ are included in the fully specified results as well. The school-by-year fixed effect controls for any fixed characteristics about the school-by-year, such as schools' disciplinary policies, the general level of safety in the school, or characteristics of the year such as the economic downturn of the late 2000s. The inclusion of teacher characteristics controls for potentially confounding predictors of teacher turnover such as experience or education. The inclusion of school/district characteristics controls for observable differences in school settings in which teachers teach.

In order to further explore the relationship between victimization and teacher turnover, we ran models that interacted the victimization measures with an indicator for elementary school. Theoretically, the act of experiencing a threat or attack from a student could differ significantly by the age of the students. In particular, a threat from a younger student may not be taken as seriously as that from an older student, and a physical attack from a younger student might be expected to inflict less harm and be less traumatic as compared to an attack from an older 
student. In the models exploring this potential difference, the interaction term between the victimization measure and the indicator for elementary school picks up the extent to which the relationship between victimization and turnover varies by school grade level.

Finally, while the controls utilized in this study eliminate many sources of bias, the biggest threat to this study is the potential for omitted variable bias. In particular, there may be characteristics of teachers, such as their teaching ability or classroom management skills, which are unobserved and would be correlated with both their likelihood of being victimized by students and their likelihood of turning over. Consequently, the results of this study should be interpreted as adjusted correlations rather than causal estimates.

\section{Results}

\section{Primary Findings}

We find teacher reports of victimization to be a consistent predictor of teacher turnover, both from the school and from the profession. Table 2 shows the results of our multinomial logistic regression models with increasing sets of controls. As shown, the raw relationship (columns 1-3) reflects a generally higher likelihood of turnover as a result of being threatened or being attacked by a student in the prior twelve months. As shown, models that include teacher controls (columns 4-6), school controls (columns 7-9), and the year fixed effects (columns 1012) reduce the magnitude of the coefficients by about a third but generally show the same relationship. Interestingly, however, the relationship is generally larger and more consistently statistically significant for incidents of threats rather than attacks.

Table 3 shows the results of the fully specified conditional multinomial logistic regression model along with corresponding odds ratios. In the top two rows, we show the relationship between threats and attacks and moving schools. As shown in columns 1 and 2, 
reporting being threatened or attacked in the last twelve months are both predictive of a greater odds of moving to a different school the following year. The relationship remains significant for threats when including both victimization predictors in the same model (columns 5 and 6). The results for leaving the profession (bottom two rows) suggest that being threatened with injury by a student is predictive of leaving the teaching profession while being physically attacked by a student is statistically non-significant.

We find that the relationship between reports of victimization and turnover is substantial in magnitude. The practical significance of our findings can be put in perspective by comparing the estimated relationships to those of covariates that the literature has established as influencing rates of teacher turnover (e.g., Borman \& Dowling, 2008; Darling-Hammond, 2000; Ingersoll, 2001; Ingersoll \& May, 2012; Johnson \& Birkeland, 2003). For instance, in the fully specified model, the estimated regression coefficient $(\beta=0.230)$ for the relationship between reporting being threatened in the last twelve months and moving schools is larger than the magnitude of the effects of a traditional teacher certification $(\beta=-0.195)$ or holding a master's degree $(\beta=$ 0.120). Similarly, the relationship between reporting being threatened and leaving the profession $(\beta=0.242)$ is approximately half the size of that for holding a traditional teacher certification $(\beta$ $=-0.421)$. These results suggest that teacher victimization has an impact on teacher turnover within a school and within the profession that is comparable to established predictors of teacher turnover or retention from the literature.

Interestingly, the relationship between reports of victimization and turnover did not consistently differ by grade level of the school. In models interacting the victimization measure with a binary indicator for being an elementary school (Table 4), the interaction term was generally non-significant. The one exception was the relationship between reporting being 
threatened in the last twelve months and leaving the teaching profession, in which case, the relationship appeared to be entirely driven by upper grade levels.

Despite the significant relationship between measures of teacher reported victimization and turnover, many teachers who experience victimization nevertheless remain in their schools or in the profession. In other words, experiences of victimization are no guarantee of teacher turnover. In the second section of the results, we explore one potential mechanism by which schools and teachers may mitigate the relationship between victimization and turnover. In particular, we explore contextual promoters of resilience with the aim of understanding how it is that teachers can be in an unsafe environment and remain teaching in that school.

\section{Promoters of Resilience}

The evidence presented thus far indicates that being victimized at school does increase the odds of both types of teacher turnover with an effect size that is comparable to or much larger than other key indicators of teacher turnover. However, a significant portion of teachers in the sample reported being threatened with injury or physically attacked by a student in the last 12 months and remained in their school or the teaching profession. To investigate this finding further, we explored the moderating effect of school characteristics that might promote resilience, thereby decreasing the chance that a victimized teacher turns over.

We find that school characteristics promoting resilience moderate the association between teacher reported victimization and a teacher leaving the profession where higher levels on the promoters of resilience factor predicts lower rates of leaving the teaching profession for teachers who are threatened or attacked. In Table 5, we show results of models in which the victimization measures are interacted with the factor analyzed measure of school characteristics promoting resilience. As shown, a standard deviation increase in this factor predicts a 
statistically significant decrease in the relationship between reporting being threatened and leaving the profession in several of the specifications. In the fully specified model (columns 5 and 6), an increase of approximately one standard deviation in the promoters of resilience factor variable eliminates the negative effect of threats on odds of turnover. The most consistent results are seen for the interaction with threats, suggesting that promoters of resilience may serve to mitigate the impact of threats on leaving the profession to a greater degree than the impact of an attack.

\section{Discussion}

Teachers play a critical role in promoting student learning, representing one of the most important predictors of student achievement gains (Nye, Konstantopoulous, \& Hedges, 2004; Rivkin, Hanushek, \& Kain, 2005). Teacher turnover, both from the school and from the profession more generally, may contribute to the loss of quality teachers thereby weakening the academic experience of students (Ronfeldt, Loeb, \& Wykoff, 2013). The literature has established the importance of working conditions as a significant predictor of teachers' decisions to move schools or leave the profession (Grissom, 2011; Johnson, Kraft, \& Papay, 2011; Ladd, 2011). Teachers' experiences of victimization represent a potentially important component of their working conditions; however, research to date has failed to fully explore the relationship between such experiences and teachers' likelihood of staying at their schools (Espelage et al., 2013). In this paper, we have expanded on the previous evidence on this topic (Zurawiecki, 2013) utilizing multiple waves of a nationally representative survey while exploring the relationship between both reported instances of threats and attacks and teacher movement across schools and out of the profession. The findings suggest that teacher reported experiences of victimization from students are a positive predictor of turnover from both the individual school 
and also the profession but that this relationship can be mitigated through contextual factors that promote resilience.

Our findings suggest that teachers' experiences of victimization contribute to turnover. In particular, we find that the relationship between reporting being threatened and attacked and changing schools or leaving the teaching profession are generally significant across model specifications, with particularly consistent results for instances of threats. The magnitude of these relationships is on par with other established contributors to teacher turnover, suggesting that victimization represents an important component in understanding turnover (Borman \& Dowling, 2008; Darling-Hammond, 2000; Ingersoll, 2001; Ingersoll \& May, 2012; Johnson \& Birkeland, 2003).

These findings suggest the importance of attention to the safety of teachers. Not only is teacher safety important in and of itself, but, minimizing teachers' experiences of victimization may increase the probability that they remain teaching in the school and remain in the profession. In our analytic sample, over one in ten teachers had been threatened or attacked by a student at their school within the previous twelve months. Although our analyses are unable to establish a causal relationship between victimization and turnover, with victimization rates at this level, a non-trivial number of teachers could be leaving their schools or the profession in part because of their victimization experiences. Higher turnover rates, in turn, have been linked to negative academic outcomes for students (Ronfeldt, Loeb, \& Wykoff, 2013). Because teacher turnover has been linked to academic outcomes for students (e.g., Ronfeldt, Loeb, \& Wykoff, 2013), addressing teacher victimization may result in a more stable workforce resulting in greater academic achievement for students.

\section{Limitations and future research}


As with any study, there are limitations to the analyses and results of this study. First is that, in virtue of being a large-scale national survey, the data used in this study relied on somewhat blunt indicators of experiencing victimization from students. In particular, we are unable to identify nuances in the victimization experience - the degree to which the threat/attack was taken seriously, the nature of the threat/attack, and so forth. For instance, being physically attacked or threatened by a first grader is a different experience than being physically attacked by a high school student. Likewise, being pushed is a different experience from being punched. Without more detail on the nature of the threats and attacks, understanding the nuances of the relationships explored is limited. For instance, the finding that threats, but not attacks, is associated with increased odds of leaving a school is seemingly counterintuitive but may be related to the nature of such threats and attacks, a detail we cannot explore given the data. Understanding this relationship will require further exploration beyond what is possible given the secondary nature of the data in this study. Further research, particularly qualitative data, could look into this finding.

A second limitation of the study related to the measures of victimization is that the measures focused only on threats of physical violence and physical attacks from students. Prior literature points to other types of victimization - harassment, theft, property damage - that the data used in this study could not explore (McMahon et al., 2014). Likewise, prior literature suggests that teachers may experience victimization from stakeholders other than students, such as other teachers, administrators, or parents (McMahon et al., 2014). It is possible, then, that relationships may vary for other forms of victimization or victimization perpetrated by other stakeholders. Future research with data that has broader measures of victimization could explore these questions. 
A third limitation of the victimization measures relates to the self-reported nature of the measures. Specifically, we relied on teachers' reports of victimization rather than more objective measures of victimization. While self-reports have a long history of use in victimization surveys, they are nevertheless subject to issues of recall and response bias (Cantor \& Lynch, 2000; Thornberry \& Krohn, 2003). We further note that such self-reports of victimization may be subject to bias in the perception of teachers. For instance, our finding that teachers report greater victimization in schools serving more racial minority students may, in part, be explained by differences in the way teachers perceive students of color and interpret their behavior or the way in which schools serving large proportions of such students respond to student misbehavior (Curran, 2017; Lindsay \& Hart, 2017; Welch \& Payne, 2010). Given these limitations, our results should be understood to represent the relationship between teachers' reports of perceived victimization and the outcomes of interest rather than objective measures of victimization.

Next, in addition to limitations in the victimization measures, we recognize that there are limitations in the dependent variables, namely the turnover indicators. In particular, our dataset limits us to exploring turnover in the year following victimization. While one would expect that an experience of victimization would likely impact the immediate decision to return to school the following year, it is nevertheless possible that experiences of victimization may be linked to turnover in future years. For instance, upon being victimized, a teacher may begin a process of exploring other locations to teach or other careers to pursue. This process, however, may not culminate in a move from the school until several years later. In this regard, then, our estimates of the relationship between victimization and turnover may underestimate the full impact on turnover as we are unable to identify any such delayed turnovers. 
Finally, we note that our study is limited with regard to the ability to fully account for all issues of selection bias. While our broad set of controls and the use of school-by-year fixed effects address a number of observable and unobservable potential confounders, we are not able to entirely preclude the possibility of omitted variable bias. Consequently, our results should be interpreted as adjusted correlations rather than causal estimates.

\section{Implications for policy and practice}

Our findings suggest the need for schools and teachers to identify and implement strategies to reduce students' acts of threats and attacks on teachers. In particular, facilitating positive expressions of frustration or anger on the part of students as opposed to violent expressions could reduce teacher turnover. The literature points to the positive benefits of school climates that include trust and dialogue between teachers and students (Cook, Gottfredson, \& Na, 2010; Thapa, Cohen, Guffey, \& Higgins-D’Alessandro, 2013). Furthermore, specific practices such as restorative justice techniques and positive behavior intervention and supports (PBIS) have shown promise in facilitating such trust and dialogue (Gonzalez, 2015; Horner et al., 2009; Vincent, Sprague, Pavel, Tobin, \& Gau, 2015).

While reducing and eliminating teacher victimization by students is ideal, our findings also suggest that schools may take proactive steps to mitigate the impact of victimization on turnover when such victimization does occur. In particular, taking measures to promote teacher resilience may increase the likelihood of teachers persisting in the face of undesirable working conditions (Aloe, Amo, \& Shanahan, 2013; Gu \& Day, 2007; Howard \& Johnson, 2004; Wei, 2012). We find that our measure of school-level factors that promote resilience moderates the relationship between victimization and teacher turnover across several model specifications. This measure of factors that promote resilience includes a number of malleable characteristics of 
the school, including the support offered by the administration, the enforcement of rules, and the cooperation between teachers. By taking proactive steps to address these components of the school environment, school leaders may be able to mitigate the negative impact of teacher victimization on turnover.

\section{Conclusion}

Teacher victimization is an important component of the teacher experience that potentially has significant implications for the teacher workforce and ultimately student achievement. We expand on the small body of evidence on the subject by exploring the relationship between teacher experiences of victimization by students and turnover from the school and profession. Our study is unique in that it utilizes a significantly larger sample size than previous studies, allowing us to explore the relative impact of two types of victimization (i.e., threats or assaults). Additionally, our methodological approach controls for unobservable school characteristics, a potential sources of bias unaddressed in previous literature. Our findings suggest that teacher experiences of both threats and assaults are significant predictors of turnover from individual schools and that threats also predict turnover from the profession. We find that the magnitude of these effects is substantively meaningful, representing comparable relationships to established contributors to teacher turnover or retention. Finally, our findings suggest a possible role for school-level factors promoting teacher resilience as a mechanism for mitigating the impact of teacher victimization on turnover.

As teacher shortages make headlines (Brenneman, 2015, August 4), renewed attention to the importance of retaining teachers, especially in schools serving our most disadvantaged youth, are particularly important. The findings of this study point towards the importance of policymakers and education practitioners focusing on teachers' experiences of victimization. In 
particular, policymakers and practitioners should take proactive steps to ensure a safe working environment for their teachers while also offering supports to teachers who do experience victimization. Our results suggest that focusing on creating supportive structures for teachers, a collaborative environment among teachers, and an emphasis on consistently enforcing school rules may be mechanisms through which to reduce the turnover of teachers who are victimized.

While our study provides important evidence on the relationship between teacher victimization and turnover, more work remains to further understand this relationship. For example, we were limited in our data to binary indicators of experiencing a threat or assault. Future research should examine these relationships utilizing data with more detail on the nature of the victimization, potentially disentangling instances that teachers consider serious and those that are more trivial. Additionally, future research should devote attention to mediating factors that may explain the mechanisms by which victimization leads to turnover, with particular attention on malleable factors that could reduce teacher turnover.

In summary, this study provides a foundation for action by educators, policymakers, and researchers with regard to teacher experiences of victimization. We have responded to the lack of research in this area (Espelage et al., 2013) while also calling attention to an overlooked aspect of the teacher experience, both of which have the potential to improve the schooling experience for teachers and students alike. 


\section{References}

Achinstein, B., Ogawa, R. T., Sexton, D., \& Freitas, C. (2010). Retaining teachers of Color: A pressing problem and a potential strategy for "hard-to-staff" schools. Review of Educational Research, 80(1), 71-107.

Allison, P. D. (2002). Missing data series: Quantitative applications in the social sciences. Thousand Oaks. CA: Sage.

Aloe, A. M., Amo, L. C., \& Shanahan, M. E. (2014). Classroom management self-efficacy and burnout: A multivariate meta-analysis. Educational Psychology Review, 26(1), 101-126.

Beltman, S., Mansfield, C., \& Price, A. (2011). Thriving not just surviving: A review of research on teacher resilience. Educational Research Review, 6(3), 185-207.

Berg, J. K., \& Cornell, D. (2016). Authoritative school climate, aggression toward teachers, and teacher distress in middle school. School Psychology Quarterly, 31(1), 122-139.

Berthelsen, M., Skogstad, A., Lau, B., \& Einarsen, S. (2011). Do they stay or do they go?: A longitudinal study of intentions to leave and exclusion from working life among targets of workplace bullying. International Journal of Manpower, 32(2), 178-193.

Bond, L., Butler, H., Thomas, L., Carlin, J., Glover, S., Bowes, G., \& Patton, G. (2007). Social and school connectedness in early secondary school as predictors of late teenage substance use, mental health, and academic outcomes. Journal of Adolescent Health, 40(4), 357-e9.

Borman, G. D., \& Dowling, N. M. (2008). Teacher attrition and retention: A meta-analytic and narrative review of the research. Review of Educational Research, 78(3), 367-409.

Brenneman, R. (2015, August $\left.4^{\text {th }}\right)$. Districts facing teacher shortages look for lifelines. Education Week. Retrieved from: 
http://www.edweek.org/ew/articles/2015/08/05/districts-facing-teacher-shortages-lookfor-lifelines.html

Cantor, D., \& Lynch, J. P. (2000). Self-report surveys as measures of crime and criminal victimization. Criminal justice, 4, 85-138.

Chamberlain, G. (1980). Analysis of covariance with qualitative data. Review of Economic Studies, 47, 225-238.

Cook, P. J., Gottfredson, D. C., \& Na, C. (2010). School crime control and prevention. Crime and Justice, 39, 313-440.

Cornell, D. G., \& Mayer, M. J. (2010). Why do school order and safety matter? Educational Researcher, 39, 7-15

Curran, F. C. (2017). The law, policy, and portrayal of zero tolerance school discipline: Examining prevalence and characteristics across levels of governance and school districts. Educational Policy, 0895904817691840.

Darling-Hammond, L. (2000). How teacher education matters. Journal of Teacher Education, 51(3), 166-173.

Deery, S., Walsh, J., \& Guest, D. (2011). Workplace aggression: The effects of harassment on job burnout and turnover intentions. Work, Employment \& Society, 25(4), 742-759.

Einarsen, S. ale, \& Raknes, B. I. (1997). Harassment in the workplace and the victimization of men. Violence and Victims, 12(3), 247-263.

Espelage, D., Anderman, E. M., Brown, V. E., Jones, A., Lane, K. L., McMahon, S. D., ... Reynolds, C. R. (2013). Understanding and preventing violence directed against teachers: Recommendations for a national research, practice, and policy agenda. American Psychologist, 68(2), 75-87. 
Goldring, R., Taie, S., Riddles, M., \& Owens, C. (2014). Teacher attrition and mobility: Results from the 2012-13 Teacher Follow-up Survey First Look. U.S. Department of Education. National Center for Education Statistics. Retrieved from: https://nces.ed.gov/pubs2014/2014077.pdf

González, T. (2015). Socializing schools: Addressing racial disparities in discipline through restorative justice. In Losen, D. (Ed.): Closing the school discipline gap: Equitable remedies for excessive exclusion, 151-165.

Gregory, A., Cornell, D., \& Fan, X. (2012). Teacher safety and authoritative school climate in high schools. American Journal of Education, 118(4), 401-425.

Grissom, J. A. (2011). Can good principals keep teachers in disadvantaged schools? Linking principal effectiveness to teacher satisfaction and turnover in hard-to-staff environments. Teachers College Record, 113(11), 2552-2585.

Gu, Q., \& Day, C. (2007). Teachers resilience: A necessary condition for effectiveness. Teaching and Teacher Education, 23, 1302-1316.

Guarino, C. M., Santibanez, L., \& Daley, G. A. (2006). Teacher recruitment and retention: A review of the recent empirical literature. Review of Educational Research, 76(2), 173208.

Hanushek, E. A., Kain, J. F., O’Brien, D. M., \& Rivkin, S. G. (2005). The market for teacher quality. National Bureau of Economic Research.

Hershcovis, M. S., \& Barling, J. (2009). Towards a multi-foci approach to workplace aggression: A meta-analytic review of outcomes from different perpetrators. Journal of Organizational Behavior, 31(1), 24-44. 
Horner, R. H., Sugai, G., \& Anderson, C. M. (2010). Examining the evidence base for schoolwide positive behavior support. Focus on Exceptional Children, 42(8), 1-16.

Howard, S., \& Johnson, B. (2004). Resilient teachers: Resisting stress and burnout. Social Psychology of Education, 7, 399-420.

Hughes, G. D. (2012). Teacher retention: Teacher characteristics, school characteristics, organizational characteristics, and teacher efficacy. The Journal of Educational Research, 105(4), 245-255.

Hunter, A. J. (2001). A cross-cultural comparison of resilience in adolescents. Journal of Pediatric Nursing, 16, 172-179.

Ingersoll, R. (2001). Teacher turnover and teacher shortages: An organizational analysis. American Educational Research Journal, 38(3), 499-534.

Ingersoll, R., \& May, H. (2012). The magnitude, destinations, and determinants of mathematics and science teacher turnover. Educational Evaluation and Policy Analysis, 34(4), 435464.

Johnson, S. M., \& Birkeland, S. E. (2003). The schools that teachers choose. Educational Leadership, 60(8), 20-24.

Johnson, S. M., Kraft, M. A., \& Papay, J. P. (2011). How context matters in high-need schools: The effects of teachers' working conditions on their professional satisfaction and their students' achievement. Project on the Next Generation of Teachers, Harvard Graduate School of Education.

Keigher, A. (2010). Teacher attrition and mobility: Results from the 2008-09 Teacher Follow Up Survey (No. NCES 2010-353). Washington, D.C.: National Center for Education Statistics: U.S. Department of Education. 
Kirby, S. N., Berends, M., \& Naftel, S. (1999). Supply and demand of minority teachers in Texas: Problems and prospects. Educational Evaluation and Policy Analysis, 21(1), 4766.

Ladd, H. F. (2011). Teachers' perceptions of their working conditions: How predictive of planned and actual teacher movement? Educational Evaluation and Policy Analysis, 33(2), 235-261.

Lankford, H., Loeb, S., \& Wyckoff, J. (2002). Teacher sorting and the plight of urban Schools: A descriptive analysis. Educational Evaluation and Policy Analysis, 42(1), 37-62.

Lindsay, C. A., \& Hart, C. M. (2017). Exposure to Same-Race Teachers and Student Disciplinary Outcomes for Black Students in North Carolina. Educational Evaluation and Policy Analysis, 0162373717693109.

Loeb, S., Darling-Hammond, L., \& Luczak, J. (2005). How teaching conditions predict teacher turnover in California schools. Peabody Journal of Education, 80(3), 44-70.

Luthar, S., Doernberger, C., \& Zigler, E. (1993). Resilience is not a unidimensional construct: Insights from a prospective study of inner-city adolescents. Developmental Psychopathology, 4, 287-299.

Mansfield, C., Beltman, S., Price, A., \& McConney, A. (2012). "Don’t sweat the small stuff:" Understanding teacher resilience at the chalkface. Teaching and Teacher Education, 28, $357-367$.

Martinez, A., McMahon, S. D., Espelage, D., Anderman, E. M., Reddy, L. A., \& Sanchez, B. (2016). Teachers’ Experiences With Multiple Victimization: Identifying Demographic, Cognitive, and Contextual Correlates. Journal of School Violence, 15(4), 387-405. https://doi.org/10.1080/15388220.2015.1056879 
Masten, A. S. (2001). Ordinary magic: Resilience processes in development. American Psychologist, 56, 227-238.

McMahon, S. D., Martinez, A., Espelage, D., Rose, C., Reddy, L. A., Lane, K., ... Brown, V. (2014). Violence Directed Against Teachers: Results from a National Study. Psychology in the Schools, 51(7), 753-766. https://doi.org/10.1002/pits.21777

Morrison, R. L. (2008). Negative relationships in the workplace: Associations with organisational commitment, cohesion, job satisfaction and intention to turnover. Journal of Management and Organization, 14(4), 330-344.

Nye, B., Konstantopoulos, S., \& Hedges, L. V. (2004). How large are teacher effects?. Educational Evaluation and Policy Analysis, 26(3), 237-257.

Rivkin, S. G., Hanushek, E. A., \& Kain, J. F. (2005). Teachers, schools, and academic achievement. Econometrica, 73(2), 417-458.

Roberts, S. D., Wilcox, P., May, D. C., \& Clayton, R. R. (2007). My school or our school? The effects of individual versus shared school experiences on teacher perceptions of safety. Journal of School Violence, 6(4), 33-60.

Ronfeldt, M., Loeb, S., \& Wyckoff, J. (2013). How teacher turnover harms student achievement. American Educational Research Journal, 50(1), 4-36.

Shernoff, E. S., Mehta, T. G., Atkins, M. S., Torf, R., \& Spencer, J. (2011). A qualitative study of the sources and impact of stress among urban teachers. School Mental Health, 3(2), $59-69$.

Stinebrickner, T. R. (1998). An empirical investigation of teacher attrition. Economics of Education Review, 17(2), 127-136. 
Stinebrickner, T. R. (2001). A dynamic model of teacher labor supply. Journal of Labor Economics, 19(1), 196-230.

Stinebrickner, T. R. (2002). An analysis of occupational change and departure from the labor force: Evidence of the reasons that teachers leave. The Journal of Human Resources, $37(1), 192-216$.

Strøm, I. F., Thoresen, S., Wentzel-Larsen, T., \& Dyb, G. (2013). Violence, bullying and academic achievement: A study of 15-year-old adolescents and their school environment. Child Abuse \& Neglect, 37(4), 243-251.

Strøm, I. F., Thoresen, S., Wentzel-Larsen, T., Hjemdal, O. K., Lien, L., \& Dyb, G. (2013). Exposure to life adversity in high school and later work participation: A longitudinal population-based study. Journal of Adolescence, 36(6), 1143-1151.

Thapa, A., Cohen, J., Guffey, S., \& Higgins-D’Alessandro, A. (2013). A review of school climate research. Review of Educational Research, 83, 357-385.

Thornberry, T. P., \& Krohn, M. D. (2003, January). Comparison of self-report and official data for measuring crime. In Measurement problems in criminal justice research: Workshop summary (pp. 43-94). Washington, DC: National Academies Press.

Tusaie, K., \& Dyer, J. (2004). Resilience: A historical review of the construct. Holistic Nurse Practitioner, 18, 3-8.

Vincent, C. G., Sprague, J. R., Pavel, M., Tobin, T. J., \& Gau, J. M. (2015). Effectiveness of schoolwide Positive Behavior Interventions and Supports in reducing racially inequitable disciplinary exclusion. In Losen, D. (Ed.): Closing the school discipline gap: Equitable remedies for excessive exclusion, 207-221. 
Wei, Y. (2012). A hierarchical approach to examine personal and school effect on teacher motivation. (Doctoral dissertation). The Ohio State University.

Welch, K., \& Payne, A. A. (2010). Racial threat and punitive school discipline. Social Problems, $57(1), 25-48$.

Wilson, C. M., Douglas, K. S., \& Lyon, D. R. (2011). Violence against teachers: Prevalence and consequences. Journal of Interpersonal Violence, 26(12), 2353-2371.

Zhang, A., Musu-Gillette, L., \& Oudekerk, B. A. (2016). Indicators of School Crime and Safety: 2015 (NCES 2016-079/NCJ 249758). National Center for Education Statistics, U.S. Department of Education, and Bureau of Justice Statistics, Office of Justice Programs, U.S. Department of Justice. Washington, D.C.

Zurawiecki, D. M. (2013). The impact of student threats and assaults on teacher attrition. Rutgers University-Graduate School of Applied and Professional Psychology. 
Table 1. Means of key variables by attacked and threatened status

\begin{tabular}{|c|c|c|c|c|c|}
\hline & $\begin{array}{c}\text { Full } \\
\text { Sample }\end{array}$ & $\begin{array}{l}\text { Attacked } \\
\text { in Last } 12 \\
\text { Months }\end{array}$ & $\begin{array}{c}\text { Not } \\
\text { Attacked } \\
\text { in Last } \\
\text { Twelve } \\
\text { Months } \\
\end{array}$ & $\begin{array}{c}\text { Threatened } \\
\text { in Last } 12 \\
\text { Months }\end{array}$ & $\begin{array}{c}\text { Not } \\
\text { Threatened } \\
\text { in Last } 12 \\
\text { Months }\end{array}$ \\
\hline \multicolumn{6}{|l|}{ Independent Variables } \\
\hline Threatened in last twelve months & 0.08 & 0.58 & 0.06 & 1.00 & 0.00 \\
\hline Attacked in last twelve months & 0.04 & 1.00 & 0.00 & 0.29 & 0.02 \\
\hline \multicolumn{6}{|l|}{ Dependent Variables } \\
\hline Left the teaching profession & 0.09 & 0.10 & 0.09 & 0.10 & 0.08 \\
\hline Moved schools & 0.07 & 0.10 & 0.07 & 0.09 & 0.07 \\
\hline \multicolumn{6}{|l|}{ Teacher characteristics } \\
\hline Female & 0.76 & 0.79 & 0.76 & 0.71 & 0.76 \\
\hline Hispanic & 0.06 & 0.06 & 0.06 & 0.06 & 0.06 \\
\hline Black & 0.08 & 0.10 & 0.07 & 0.11 & 0.07 \\
\hline Asian Pacific Islander & 0.02 & 0.02 & 0.02 & 0.02 & 0.02 \\
\hline Indian & 0.01 & 0.01 & 0.01 & 0.01 & 0.01 \\
\hline Master's degree & 0.48 & 0.44 & 0.48 & 0.46 & 0.48 \\
\hline Education degree & 0.63 & 0.70 & 0.62 & 0.62 & 0.63 \\
\hline Regular state certification & 0.88 & 0.83 & 0.88 & 0.84 & 0.89 \\
\hline Vector of experience dummies (1-50 years) & - & - & - & - & - \\
\hline Vector of grade taught dummies (K-12) & - & - & - & - & - \\
\hline \multicolumn{6}{|l|}{ School and district characteristics } \\
\hline Eligible for free or reduced lunch (\%) & 39.31 & 50.62 & 38.85 & 48.48 & 38.52 \\
\hline Hispanic $(\%)$ & 15.98 & 18.02 & 15.90 & 17.09 & 15.89 \\
\hline Black $(\%)$ & 15.89 & 25.43 & 15.50 & 26.75 & 14.96 \\
\hline Asian Pacific Islander (\%) & 3.71 & 3.50 & 3.72 & 3.27 & 3.74 \\
\hline Native American $(\%)$ & 1.36 & 1.51 & 1.35 & 1.74 & 1.33 \\
\hline Urban & 0.26 & 0.37 & 0.25 & 0.38 & 0.25 \\
\hline Rural & 0.23 & 0.17 & 0.23 & 0.18 & 0.24 \\
\hline Enrollment (100s) & 8.15 & 7.03 & 8.20 & 8.75 & 8.10 \\
\hline Special education school & 0.00 & 0.03 & 0.00 & 0.01 & 0.00 \\
\hline Alternative school & 0.01 & 0.01 & 0.01 & 0.02 & 0.01 \\
\hline Middle School & 0.18 & 0.14 & 0.19 & 0.21 & 0.18 \\
\hline Secondary School & 0.28 & 0.13 & 0.28 & 0.31 & 0.28 \\
\hline Combined K-12 School & 0.03 & 0.04 & 0.03 & 0.04 & 0.03 \\
\hline \multicolumn{6}{|l|}{$\begin{array}{l}\text { Contributors to resiliency (1-4; strongly } \\
\text { disagree to strongly agree) }\end{array}$} \\
\hline Admin supports & 3.29 & 3.05 & 3.30 & 2.97 & 3.32 \\
\hline Parent supports & 2.65 & 2.38 & 2.66 & 2.24 & 2.69 \\
\hline Admin enforces rules & 3.35 & 3.14 & 3.36 & 3.01 & 3.38 \\
\hline Teachers enforce rules & 2.86 & 2.75 & 2.87 & 2.53 & 2.89 \\
\hline Teachers share beliefs & 3.22 & 3.14 & 3.22 & 3.05 & 3.23 \\
\hline Teachers cooperate & 3.17 & 2.99 & 3.18 & 2.92 & 3.19 \\
\hline Misbehavior interferes with teaching & 2.12 & 2.53 & 2.11 & 2.73 & 2.07 \\
\hline Staff recognized for job well done & 2.98 & 2.80 & 2.98 & 2.71 & 3.00 \\
\hline$n$ & 104,840 & 3,300 & 101,540 & 8,510 & 96,330 \\
\hline
\end{tabular}

Note. Variables without units specified are binary variables allowing their means to be interpreted as proportions 
Table 2. Coefficients and standard errors from multinomial logistic regressions predicting moving or leaving from threatened/attacked in last twelve months with progressive addition of control variables

\begin{tabular}{|c|c|c|c|c|c|c|c|c|c|c|c|c|}
\hline & $(1)$ & $(2)$ & (3) & (4) & $(5)$ & $(6)$ & $(7)$ & $(8)$ & $(9)$ & $(10)$ & (11) & $(12)$ \\
\hline \multicolumn{13}{|l|}{ Mover } \\
\hline \multicolumn{13}{|l|}{ Threatened in last } \\
\hline twelve months & $(0.0684)$ & & $(0.0774)$ & $(0.0694)$ & & $(0.0779)$ & $(0.0699)$ & & $(0.0779)$ & $(0.0700)$ & & $(0.0780)$ \\
\hline \multirow[t]{2}{*}{$\begin{array}{l}\text { Attacked in last } \\
\text { twelve months }\end{array}$} & & $0.396 * * *$ & $0.222 * *$ & & $0.233 * *$ & 0.0919 & & $0.202 * *$ & 0.0977 & & $0.202 * *$ & 0.101 \\
\hline & & $(0.0955)$ & $(0.108)$ & & $(0.0984)$ & $(0.110)$ & & $(0.0992)$ & $(0.111)$ & & $(0.0990)$ & $(0.110)$ \\
\hline \multicolumn{13}{|l|}{ Leaver } \\
\hline \multicolumn{13}{|l|}{ Threatened in last } \\
\hline twelve months & $(0.0620)$ & & $(0.0669)$ & $(0.0622)$ & & $(0.0672)$ & $(0.0630)$ & & $(0.0679)$ & $(0.0630)$ & & $(0.0678)$ \\
\hline \multirow[t]{2}{*}{$\begin{array}{l}\text { Attacked in last } \\
\text { twelve months }\end{array}$} & & 0.168 & 0.0273 & & $0.188 *$ & 0.0497 & & 0.128 & 0.0341 & & 0.134 & 0.0368 \\
\hline & & $(0.104)$ & $(0.113)$ & & $(0.105)$ & $(0.114)$ & & $(0.106)$ & $(0.115)$ & & $(0.106)$ & $(0.114)$ \\
\hline Teacher controls & & & & $\mathrm{X}$ & $X$ & $\mathrm{X}$ & $\mathrm{X}$ & $\mathrm{X}$ & $\mathrm{X}$ & $\mathrm{X}$ & $\mathrm{X}$ & $\mathrm{X}$ \\
\hline School controls & & & & & & & $\mathrm{X}$ & $\mathrm{X}$ & $\mathrm{X}$ & $\mathrm{X}$ & $\mathrm{X}$ & $\mathrm{X}$ \\
\hline Year-fixed effects & & & & & & & & & & $\mathrm{X}$ & $\mathrm{X}$ & $\mathrm{X}$ \\
\hline
\end{tabular}

Note. Sample size for models with school-by-year fixed effect reflect a smaller sample that contains variation in the outcome variable within school-by-years as estimates are based on such within school-by-year variation. All models include weights and adjustment of standard errors to account for clustering in the sample design. Sample sizes are rounded to the nearest ten to comply with restricted data license obligations.

$* * * \mathrm{p}<0.01, * * \mathrm{p}<0.05, * \mathrm{p}<0.1$ 
Table 3. Coefficients and standard errors from multinomial conditional logistic regressions predicting moving or leaving from threatened/attacked in last twelve months

\begin{tabular}{|c|c|c|c|c|c|c|}
\hline & (1) & $\begin{array}{l}\text { Odds } \\
\text { Ratio } \\
\text { (2) }\end{array}$ & (3) & $\begin{array}{l}\text { Odds } \\
\text { Ratio } \\
\text { (4) }\end{array}$ & (5) & $\begin{array}{l}\text { Odds } \\
\text { Ratio } \\
(6)\end{array}$ \\
\hline \multicolumn{7}{|l|}{ Mover } \\
\hline Threatened in last twelve months & $\begin{array}{c}0.257 * * * \\
(0.0517)\end{array}$ & 1.293 & & & $\begin{array}{c}0.230^{* * *} \\
(0.0546)\end{array}$ & 1.258 \\
\hline Attacked in last twelve months & & & $\begin{array}{c}0.245^{* * *} * \\
(0.0788)\end{array}$ & 1.278 & $\begin{array}{c}0.134 \\
(0.0831)\end{array}$ & 1.143 \\
\hline \multicolumn{7}{|l|}{ Leaver } \\
\hline Threatened in last twelve months & $\begin{array}{c}0.236 * * * \\
(0.0465)\end{array}$ & 1.266 & & & $\begin{array}{c}0.242 * * * \\
(0.0489)\end{array}$ & 1.273 \\
\hline Attacked in last twelve months & & & $\begin{array}{c}0.0918 \\
(0.0775)\end{array}$ & 1.096 & $\begin{array}{l}-0.0313 \\
(0.0816)\end{array}$ & 0.969 \\
\hline
\end{tabular}

Teacher controls

School-by-year fixed effects

$\begin{array}{lll}X & X & X \\ X & X & X\end{array}$

\begin{tabular}{l}
\hline$n$ \\
$\begin{array}{l}\text { Note. Reduced sample size is a result of the use of conditional multinomial logit models which estimate results within school-by- } \\
\text { years that have variation in the outcome measure. Sample sizes are rounded to the nearest ten to comply with restricted data license } \\
\text { obligations. }\end{array}$
\end{tabular}
obligations. 
Table 4. Coefficients and standard errors from multinomial conditional logistic regressions predicting moving or leaving from threatened/attacked in last twelve months interacted with school level

\begin{tabular}{|c|c|c|c|c|c|c|}
\hline & $(1)$ & $\begin{array}{c}\text { Odds } \\
\text { Ratio } \\
(2)\end{array}$ & $(3)$ & $\begin{array}{c}\text { Odds } \\
\text { Ratio } \\
(4)\end{array}$ & $(5)$ & $\begin{array}{c}\text { Odds } \\
\text { Ratio } \\
(6)\end{array}$ \\
\hline \multicolumn{7}{|l|}{ Mover } \\
\hline Threatened in last twelve months & $\begin{array}{c}0.265^{* * *} * \\
(0.0600)\end{array}$ & 1.303 & & & $\begin{array}{c}0.251 * * * \\
(0.0622)\end{array}$ & 1.285 \\
\hline Attacked in last twelve months & & & $\begin{array}{c}0.222 * * \\
(0.111)\end{array}$ & 1.249 & $\begin{array}{c}0.103 \\
(0.115)\end{array}$ & 1.108 \\
\hline Threatened in last twelve months * Elementary & $\begin{array}{c}-0.0368 \\
(0.118)\end{array}$ & 0.964 & & & $\begin{array}{r}-0.0995 \\
(0.129)\end{array}$ & 0.909 \\
\hline Attacked in last twelve months * Elementary & & & $\begin{array}{l}0.0444 \\
(0.157)\end{array}$ & 1.045 & $\begin{array}{c}0.0909 \\
(0.170)\end{array}$ & 1.095 \\
\hline \multicolumn{7}{|l|}{ Leaver } \\
\hline Threatened in last twelve months & $\begin{array}{c}0.288 * * * \\
(0.0516)\end{array}$ & 1.334 & & & $\begin{array}{c}0.295^{* * *} * \\
(0.0537)\end{array}$ & 1.343 \\
\hline Attacked in last twelve months & & & $\begin{array}{c}0.104 \\
(0.102)\end{array}$ & 1.110 & $\begin{array}{c}-0.0543 \\
(0.106)\end{array}$ & 0.947 \\
\hline Threatened in last twelve months * Elementary & $\begin{array}{c}-0.265^{* *} \\
(0.118)\end{array}$ & 0.767 & & & $\begin{array}{c}-0.303 * * \\
(0.129)\end{array}$ & 0.739 \\
\hline Attacked in last twelve months * Elementary & & & $\begin{array}{r}-0.0287 \\
(0.156)\end{array}$ & 0.972 & $\begin{array}{c}0.133 \\
(0.168)\end{array}$ & 1.142 \\
\hline Teacher controls & $\mathrm{X}$ & & $\mathrm{X}$ & & $\mathrm{X}$ & \\
\hline School-by-year fixed effects & $\mathrm{X}$ & & $\mathrm{X}$ & & $\mathrm{X}$ & \\
\hline$n$ & 59,920 & & 59,920 & & 59,920 & \\
\hline
\end{tabular}

Note. Reduced sample size is a result of the use of conditional multinomial logit models which estimate results within school-by-years that have variation in the outcome measure. Sample sizes are rounded to the nearest ten to comply with restricted data license obligations. 
Table 5. Coefficients and standard errors from multinomial conditional logistic regressions predicting moving or leaving from threatened/attacked in last twelve months interacted with contextual promoters of resiliency factor

\begin{tabular}{|c|c|c|c|c|c|c|}
\hline 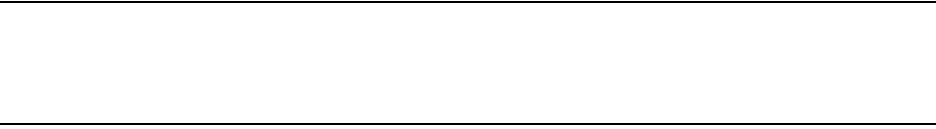 & (1) & $\begin{array}{c}\text { Odds } \\
\text { Ratio } \\
(2)\end{array}$ & (3) & $\begin{array}{c}\text { Odds } \\
\text { Ratio } \\
(4)\end{array}$ & $(5)$ & $\begin{array}{c}\text { Odds } \\
\text { Ratio } \\
(6)\end{array}$ \\
\hline \multicolumn{7}{|l|}{ Mover } \\
\hline Threatened in last twelve months & $\begin{array}{l}0.143 * * \\
(0.0580)\end{array}$ & 1.153 & & & $\begin{array}{c}0.108^{*} \\
(0.0617)\end{array}$ & 1.114 \\
\hline Attacked in last twelve months & & & $\begin{array}{c}0.208 * * \\
(0.081)\end{array}$ & 1.231 & $\begin{array}{l}0.179 * * \\
(0.0861)\end{array}$ & 1.195 \\
\hline Threatened in last twelve months $*$ Contextual protective factor & $\begin{array}{c}-0.0939^{*} \\
(0.0516)\end{array}$ & 0.910 & & & $\begin{array}{l}-0.105^{*} \\
(0.0549)\end{array}$ & 0.900 \\
\hline Attacked in last twelve months * Contextual protective factor & & & $\begin{array}{c}-0.0334 \\
(0.0823)\end{array}$ & 0.967 & $\begin{array}{l}0.0221 \\
(0.082)\end{array}$ & 1.022 \\
\hline Contextual protective factor & $\begin{array}{c}-0.221 * * * \\
(0.0197)\end{array}$ & 0.801 & $\begin{array}{c}-0.236^{* * *} \\
(0.0189)\end{array}$ & 0.789 & $\begin{array}{c}-0.221 * * * \\
(0.0197)\end{array}$ & 0.801 \\
\hline \multicolumn{7}{|l|}{ Leaver } \\
\hline Threatened in last twelve months & $\begin{array}{c}0.102 * \\
(0.0534)\end{array}$ & 1.107 & & & $\begin{array}{c}0.110^{*} \\
(0.0565)\end{array}$ & 1.116 \\
\hline Attacked in last twelve months & & & $\begin{array}{c}0.0176 \\
(0.084)\end{array}$ & 1.017 & $\begin{array}{c}-0.027 \\
(0.0872)\end{array}$ & 0.973 \\
\hline Threatened in last twelve months $*$ Contextual protective factor & $\begin{array}{c}-0.142 * * * \\
(0.0452)\end{array}$ & 0.867 & & & $\begin{array}{c}-0.134 * * * \\
(0.0484)\end{array}$ & 0.874 \\
\hline Attacked in last twelve months * Contextual protective factor & & & $\begin{array}{c}-0.111 \\
(0.0771)\end{array}$ & 0.894 & $\begin{array}{r}-0.0329 \\
(0.078)\end{array}$ & 0.967 \\
\hline Contextual protective factor & $\begin{array}{c}-0.150 * * * \\
(0.0174)\end{array}$ & 0.860 & $\begin{array}{c}-0.170 * * * \\
(0.0167)\end{array}$ & 0.843 & $\begin{array}{c}-0.150 * * * \\
(0.0174)\end{array}$ & 0.860 \\
\hline Teacher controls & $\mathrm{X}$ & & $\mathrm{X}$ & & $\mathrm{X}$ & \\
\hline School-by-year fixed effects & $\mathrm{X}$ & & $\mathrm{X}$ & & $\mathrm{X}$ & \\
\hline$n$ & 59,920 & & 59,920 & & 59,920 & \\
\hline
\end{tabular}

Note. Reduced sample size is a result of the use of conditional multinomial logit models which estimate results within school-by-years that have variation in the outcome measure. Sample sizes are rounded to the nearest ten to comply with restricted data license obligations. 


\section{Appendix A: Survey questions for independent and dependent variables}

\section{Independent Variables:}

Has a student FROM THIS SCHOOL threatened to injure you IN THE PAST 12 MONTHS? (Yes/No)

Has a student FROM THIS SCHOOL physically attacked you IN THE PAST 12 MONTHS? (Yes/No)

\section{Protective Factor Variables Questionnaire Items:}

To what extent do you agree or disagree with each of the following statements? (strongly agree, somewhat agree, somewhat disagree, strongly disagree):

The school administration's behavior toward the staff is supportive and encouraging.

I receive a great deal of support from parents for the work I do.

My principal enforces school rules for student conduct and backs me up when I need it.

Rules for student behavior are consistently enforced by teachers in this school, even for students who are not in their classes.

Most of my colleagues share my beliefs and values about what the central mission of the school should be.

There is a great deal of cooperative effort among the staff members.

The level of student misbehavior in this school (such as noise, horseplay or fighting in the halls, cafeteria, or student lounge) interferes with my teaching.

In this school, staff members are recognized for a job well done. 